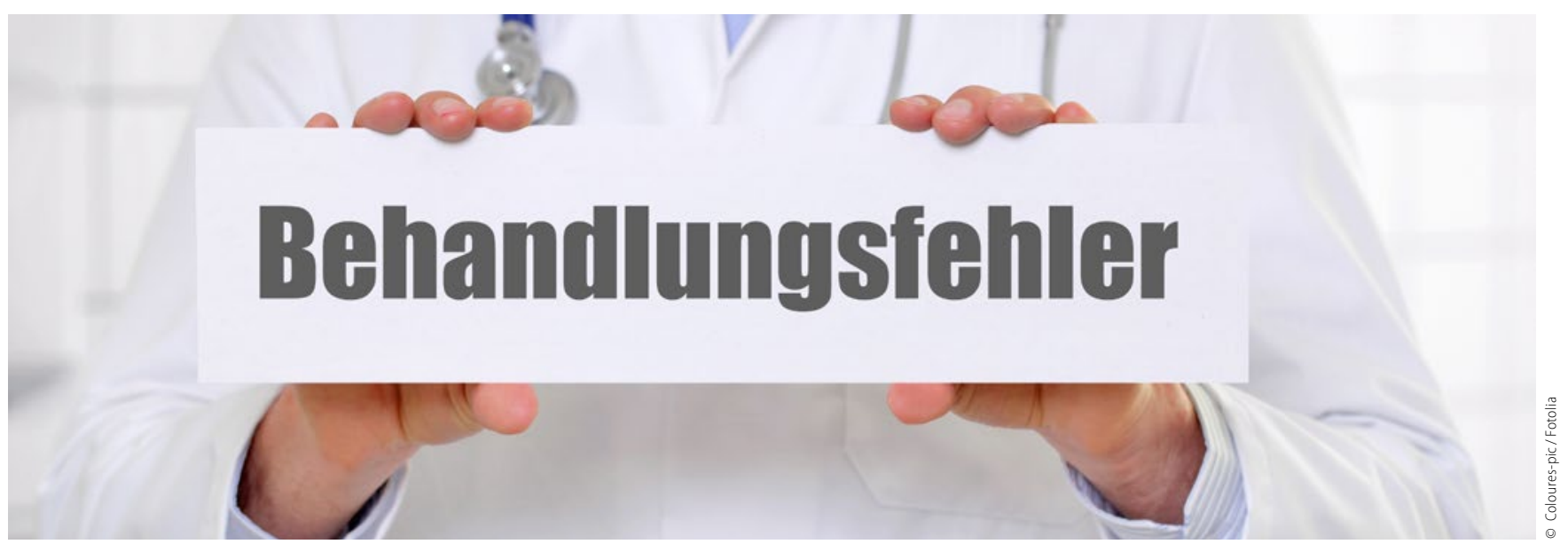

\title{
MDS fordert verpflichtendes Meldesystem
}

\author{
Zum fünften Mal haben die Medizinischen Dienste der Krankenversicherung (MDK) in diesem \\ Jahr ihre Statistik über Behandlungsfehler vorgelegt. Auffallend bei den Fehlern ist das hetero- \\ gene Bild der Erkrankungen und Behandlungen. Die MDK-Statistik ist nicht repräsentativ und die \\ Zahlen sind somit streitbar.
}

\begin{abstract}
Insgesamt 14.828 Fälle von vermuteten Behandlungsfehlern haben die Gutachter des MDK im vergangenen Jahr deutschlandweit unter die Lupe genommen. Damit nahm die Zahl der gesetzlich Versicherten, die einen Fehler im Verlauf der Behandlung vermuteten und Kontakt mit ihrer Kasse aufnahmen, seit dem Inkrafttreten des Patientenrechtegesetzes 2013 weiterhin zu. Bei rund jedem vierten Fall stellten die MDK-Gutachter einen Fehler im Behandlungsverlauf fest, der zu einem Schaden bei dem Patienten führte. Dies entspricht dem Niveau der vergangenen drei Jahre. Zwei Drittel der Vorwürfe betrafen stationäre Behandlungen. Ein Drittel bezog sich auf den ambulanten Sektor. Die meisten Verdachtsfälle entfielen auf die Fachgebiete Orthopädie und Unfallchirurgie.
\end{abstract}

\section{Keine Rückschlüsse auf gefährliche Behandlung}

Bei der Bestätigungsquote zeigt sich ein anderes Bild. Den höchsten Prozentsatz an bestätigten Fehlern fanden die Gutachter mit 52,5 Prozent von 768 Fällen in der Pflege. In der Zahnmedizin waren es 41 Prozent von 1.101 begutachteten Fällen (451 Fälle).Der MDK erklärte die Zahlen für Pflege und Zahnmedizin damit, dass vor allem bei Behandlungen in diesen Fachgebieten Fehler „leichter für den Patienten anhand der vorliegenden Beschwerden (Schäden) erkennbar sind." Gleichzeitig wies Prof. Dr. Astrid Strobel vom MDK Bayern darauf hin, dass eine hohe Bestätigungsquote keine Rückschlüsse auf gefährlichere Behandlungen in einem Fachgebiet zulasse, weil die Datenbasis nicht die Gesamtzahl der Behandlungen und Behandlungsfehler erfasse. Der stellvertretende Geschäftsführer des Medizinischen Dienstes des Spitzenverbands der Krankenkassen (MDS), Dr. Stefan Gronemeyer, forderte eine Meldepflicht für Behandlungsfehler. „Damit kann eine zuverlässige Daten- basis geschaffen werden, die Spekulationen beendet und mehr Gewissheit über die Wirkung von Sicherheitsmaßnahmen bringt.“ Als Beispiel nannte Gronemeyer Großbritannien, wo die Meldepflicht für die Leistungserbringer gelte.

\section{Verwaltungsdenken führt zu Misstrauenskultur}

Der Bundesvorsitzende des Freien Verbands Deutscher Zahnärzte (FVDZ), Harald Schrader, wies den Vorschlag des MDS als unsinnig und kontraproduktiv zurück. „Diese Art von Verwaltungsdenken führt uns immer weiter in eine Misstrauenskultur und verbessert keine einzige Behandlung“, erklärte Schrader. Medizinische Behandlungen ließen sich nicht wie rein technische Vorgänge katalogisieren, analysieren und qualifizieren.

„Insgesamt gibt es in der Zahnmedizin jährlich etwa 90 Millionen Behandlungsfälle gesetzlich versicherter Patienten. Diese Gesamtzahl der Arzt-Patienten-Kontakte gilt es, im Verhältnis zu den Zahlen des MDK zu sehen. Wo Menschen wirken, passieren auch Fehler." Die Zahnärzteschaft gehe grundsätzlich offen mit Fehlern um. Jeder Arzt sei durch das Patientenrechtegesetz verpflichtet, Patienten über unerwünschte Ereignisse oder das Nichterreichen des Behandlungsziels zu informieren. Der Patient habe dann vielfältige Möglichkeiten - von der Zweitmeinung über Gutachterverfahren bis zu Patientenberatungsstellen und Schlichtungsstellen - prüfen zu lassen, ob ein Behandlungsfehler vorliegt.

„Nicht die Datensammelwut von Kontrolleuren hilft dem Patienten, sondern ein gut ausgebildeter, motivierter Arzt oder Zahnarzt, der sich Zeit für die Probleme des Patienten nehmen kann und nicht fürchten muss, wegen angeblich unwirtschaftlicher Behandlungsweise mit Regressen der Kostenträger überzogen zu werden“, so Schrader weiter. 